\title{
The Health Behaviour Inventory: Initial Development, Factor Structure and Evidence of Reliability
}

\author{
Godwin Awabil \\ Associate Professor, Counselling Centre, \\ University of Cape Coast, Ghana \\ Corresponding Author \\ Eric Anane \\ Institute of Education, \\ University of Cape Coast, Ghana
}

Doi: $10.2478 /$ jesr-2018-0015

\begin{abstract}
This study explored the factor structure and reliability of a new Health Behaviour Inventory (HBI) to assess the health behaviour of adults. Data in this study were collected from a total of 581 postgraduate students of the University of Cape Coast. The HBI was subjected to principal component factor analysis with Varimax (Kaiser Normalization). The Kaiser Meyer-Olkin measure was used to verify the sampling adequacy for the factor analysis, which yielded KMO of .808. This indicated that the sample size was adequate and factor analysis could be performed on the data set. Bartlett's test of Sphericity $\left(X^{2}=\right.$ 8133.626, $p=0.000$ ) was significant for the sample. The analysis yielded six factors with robust reliabilities. The six factors were: alcohol intake, smoking, dietary behaviour, physical exercise, salt intake and weight management. With respect to the reliability of the instrument, the HBI items yielded a Cronbach's alpha of .792 for the total scale. The exploratory factor analyses demonstrated good factor structure and internal consistency. However, since this is the first study to explore the HBI structure, the researchers recommended that further investigations into the psychometric properties (such as the predictive validity) of the instrument be carried out.
\end{abstract}

Keywords: Health Behaviour Inventory, exploratory factor analysis, counselling, lifestyle modifications, assessment

\section{Introduction}

Several World Health Organisation reports over the recent years have highlighted the high incidence of chronic diseases such as diabetes, coronary heart disease, hypertension and cancer. The contributory factors include unhealthy diets, alcohol and tobacco use and sedentary lifestyles (Jepson, Harris, Plate, \& Tannahill, 2010). More often than not, doctors prescribe drugs for patients in order to manage these chronic diseases with the view to improving health. It is, however, important to note that improvement in health is not only brought about by taking drugs but also through the adoption of healthy lifestyle. One chronic disease that is associated with lifestyle is hypertension (high blood pressure) and it is of serious concern in Ghana.

A study conducted by Addo, Amoah and Koram (2006) in rural Accra of Ghana showed that the prevalence of hypertension was relatively high, but awareness and control were low. In a related study, Agyemang, Bruijnzeels and Owusu-Dabo (2006) found that in the regional capital called Kumasi and four villages in the Ashanti Region of Ghana; the overall prevalence of 
hypertension was $29.4 \%$. Among these hypertensive persons, $34 \%$ were aware, $28 \%$ were receiving treatment and only $6.2 \%$ were adequately controlled below $\mathrm{BP}<140 / 90 \mathrm{mmHg}$.

Therefore, Agyemang et al. (2006), recommended, among others, that increasing awareness and simple preventive measures such as promotion of physical activity, normalizing body weight and reduction of salt intake, present the best hope for reducing the impact of hypertension on morbidity and mortality. Similarly, a number of experts in the field of medicine strongly believe that lifestyle modifications or non-pharmacological interventions can favourably affect blood pressure and reduce cardiovascular risk. For instance, Nadar and Lip (2011) opined that the management of hypertension would be incomplete without lifestyle modifications. Similarly, Sharma, Frishman and Ghandhi (2011) posited that a combination of both pharmacological and non-pharmacological interventions is required for optimal blood pressure control in most patients. The major lifestyle modifications for reducing blood pressure that have sufficient experimental evidence include weight reduction, dietary changes, reduction in salt intake, physical activity, reduction in alcohol consumption and smoking cessation (Wexler \& Aukerman, 2006; Costa, 2002; Bhatt, Luqman Arafath \& Guleria, 2007; Sainani, 2003; Sharma et al, 2011). Thus, hypertensive patients need to make lifestyle modifications to complement drug therapy.

Besides, people with normal blood pressure would need to be encouraged to maintain good health behaviour in order to keep blood pressure in normal range. Similarly, people at the prehypertension stage have an increased risk of future hypertension and would, therefore, require to make lifestyle modifications. In order to contribute to the prevention and effective management of high blood pressure, there is the need for clinicians and counsellors in Ghana to use relevant instruments to assess the health behaviour of clients. However, to the best of the current researchers' knowledge, there is no instrument that has been developed for measuring health behaviour in Ghana. Clinical personnel rely on the interview technique to assess the health behaviour of their patients without using valid and reliable instruments. It is against this background that the researchers decided to develop an instrument to assess health behaviour of adults. The purpose of the study was to explore the factor structure of the health behaviour inventory using exploratory factor analysis and to investigate the reliability indices of the instrument.

\section{Method}

\subsection{Instrument development}

The instrument was developed based on existing literature relating to lifestyle modifications. The items were crafted after a careful study of the research publications of Bhatt, Luqman-Arafath and Guleria (2007), Kaplan (1987), Wexler and Aukerman (2006), Costa (2002) and Sainani (2003). Other sources reviewed were authored by Nadar and Lip (2011), Ribeiro, Ribeiro, Dias, Ribeiro, Castro, Suarez-Varela, and Cotta (2011) and Forrester, Adeyemo, Soarres-Wynter, Sargent, Bennett, Wilks, Luke, Prewitt, Kramer and Cooper (2005). In addition, experts in the fields of Counselling and Health provided useful input which facilitated the development of the inventory. From the analyses of the literature, the initial version of the $\mathrm{HBI}$ consisted of 28 items. Each item was scored using a Likert-type scale (4 - Very true, 3 - True, 2 - Fairly true, 1 - Not true). High score on the scale is indicative of poor health behaviour. In other words, the higher the scale score, the poorer the health behaviour and vice versa.

\subsection{Participants}

The sample comprised sandwich postgraduate students in the College of Education Studies of the University of Cape Coast during the 2016/2017 academic year. The students in the College of Education Studies read M.Ed./MA programmes with specializations in areas such as administration, guidance and counselling, teacher education, physical/health education and science education. Students from 9 out of 14 specializations were randomly selected for the study. Table 1 represents the socio-demographic characteristics of the sample. 
Table 1: Socio-demographic Characteristics of the Sample

\begin{tabular}{|c|c|c|}
\hline Items & Frequency & Percentages \\
\hline \multicolumn{3}{|l|}{ Year of Study } \\
\hline First year & 319 & 54.9 \\
\hline Second year & 262 & 45.1 \\
\hline \multicolumn{3}{|l|}{ Gender } \\
\hline Male & 290 & 49.9 \\
\hline Female & 291 & 50.1 \\
\hline \multicolumn{3}{|l|}{ Marital Status } \\
\hline Single & 213 & 36.7 \\
\hline Married & 354 & 60.9 \\
\hline Divorced & 10 & 1.7 \\
\hline Separated & 3 & .5 \\
\hline Widowed & 1 & .2 \\
\hline \multicolumn{3}{|l|}{ Ages (years) } \\
\hline Below 25 & 18 & 3.1 \\
\hline $25-34$ & 248 & 42.7 \\
\hline $35-44$ & 217 & 37.3 \\
\hline $45-54$ & 90 & 15.5 \\
\hline 54 and above & 8 & 1.4 \\
\hline \multicolumn{3}{|l|}{ Employment Status } \\
\hline Employed by Gov't/NGO & 520 & 89.5 \\
\hline Self - employed & 29 & 5.0 \\
\hline Unemployed & 32 & 5.5 \\
\hline \multicolumn{3}{|l|}{ Religion } \\
\hline Islam & 42 & 7.2 \\
\hline Christianity & 531 & 91.4 \\
\hline Traditional & 4 & .7 \\
\hline Others & 4 & .7 \\
\hline \multicolumn{3}{|l|}{ Blood Pressure Status } \\
\hline Normal blood pressure & 481 & 82.8 \\
\hline High blood pressure & 33 & 5.7 \\
\hline Low blood pressure & 10 & 1.7 \\
\hline I don't know & 57 & 9.8 \\
\hline
\end{tabular}

A total of 581 respondents participated in this study. The sample was heterogeneous with regard to socio-demographic data. It consisted of $54.9 \%$ and $45.1 \%$ first and second year sandwich masters' students respectively. There was an even distribution of male and female respondents. Of the 581 respondents, $213(36.7 \%)$ were single and $354(60.9 \%)$ married. Ten $(1.7 \%), 3(.5 \%)$ and $1(.2 \%)$ were divorced, separated and widowed respectively. Eight percent of the respondents were between the ages of 25 to 44 years, with $15.5 \%, 3.1 \%$ and $1.4 \%$ being between the ages of $45-54$ years, below 25 years and 55+ years respectively. Of 581 respondents, $89.5 \%$ of them were employed with the remaining $10.5 \%$ being self- employed and unemployed. The respondents were predominantly Christians $(91.4 \%)$ and the remaining were Muslims and traditionalists. Four hundred and eighty-one $(82.8 \%), 33(5.7 \%)$, and $10(1.7 \%)$ of the respondents reported that they had normal, high and low blood pressure respectively. Fifty-seven $(9.8 \%)$ of them said they did not know their blood pressure status.

\subsection{Data collection procedure}

Ethical clearance was obtained from the University of Cape Coast prior to the administration of the health behaviour inventory. Participants were informed about the purpose and the voluntary nature of study. Also, informed consent from participants was sought before the inventory was administered. The questionnaire was administered to participants in lecture theatres. It took each participant about 15 minutes to complete the instrument. 


\section{Results}

\subsection{Factor analysis}

The 28-item of HBI was subjected to principal component factor analysis using SPSS v21 with the rotation method of Varimax with Kaiser Normalization. Prior to the analysis, the statistical assumptions for principal component analysis were met. The Kaiser Meyer-Olkin measure were employed to verified the sampling adequacy for the factor analysis, which yielded $K M O=.808$. This value is a meritorious (Hutcheson \& Sofroniou, 1999) for the present data set. The KMO value is well above the acceptable limit of .5 (Field, 2013). This indicates that the sample size of the data is adequate and factor analysis can be used on the data set. Bartlett's test of Sphericity was significant for the sample $\left[X^{2}(581)=8133.626, p=0.000\right]$, which indicated that the set of correlations in the correlation matrix was significantly differently from zero and suitable for the factor analysis. An initial analysis was run to obtain eigenvalues for each factor in the data. Eight factors had eigenvalues over Kaiser's criterion of 1 and in combination explained $64.76 \%$ of the variance. The same number of factors was indicated by scree plot. However, the 8-factor structure was rejected because two factors had one item each. These items were "I avoid skipping meals" and "I do not check my body mass index (BMI) when I go for treatment". Consequently, six factors were retained with an explained variance of $57.16 \%$. Table 2 shows the total variance explained.

Table 2: Total Variance Explained

\begin{tabular}{|c|c|c|c|c|c|c|c|c|c|}
\hline \multirow[b]{2}{*}{ Component } & \multicolumn{3}{|c|}{ Initial Eigenvalues } & \multicolumn{3}{|c|}{$\begin{array}{c}\text { Extraction Sums of Squared } \\
\text { Loadings }\end{array}$} & \multicolumn{3}{|c|}{$\begin{array}{c}\text { Rotation Sums of Squared } \\
\text { Loadings }\end{array}$} \\
\hline & Total & $\begin{array}{c}\% \text { of } \\
\text { Variance }\end{array}$ & $\begin{array}{c}\text { Cumulative } \\
\%\end{array}$ & Total & $\begin{array}{c}\% \text { of } \\
\text { Variance }\end{array}$ & $\begin{array}{c}\text { Cumulative } \\
\%\end{array}$ & Total & $\begin{array}{c}\% \text { of } \\
\text { Variance }\end{array}$ & $\begin{array}{c}\text { Cumulative } \\
\%\end{array}$ \\
\hline 1 & 5.243 & 18.725 & 18.725 & 5.243 & 18.725 & 18.725 & 4.274 & 15.264 & 15.264 \\
\hline 2 & 3.242 & 11.579 & 30.304 & 3.242 & 11.579 & 30.304 & 2.728 & 9.744 & 25.008 \\
\hline 3 & 2.397 & 8.562 & 38.866 & 2.397 & 8.562 & 38.866 & 2.541 & 9.075 & 34.083 \\
\hline 4 & 2.160 & 7.716 & 46.582 & 2.160 & 7.716 & 46.582 & 2.508 & 8.956 & 43.039 \\
\hline 5 & 1.704 & 6.087 & 52.669 & 1.704 & 6.087 & 52.669 & 2.381 & 8.505 & 51.544 \\
\hline 6 & 1.257 & 4.489 & 57.159 & 1.257 & 4.489 & 57.159 & 1.572 & 5.615 & 57.159 \\
\hline
\end{tabular}

\subsection{Rotated Matrix}

Table 3 shows the distribution of the items among the six factors and their loadings after rotation. An item was considered to be included in a factor if it had a factor loading of at least .30. According to Henson and Roberts (2006), at least two or three variables must load on a factor in order to make the interpretation meaningful.

Table 3: Rotated Component Matrix Showing Factor Loadings and Eigenvalues with the Amount of Variance Explained for the Health Behaviour Inventory

\begin{tabular}{|c|c|c|c|c|c|c|}
\hline \multirow{2}{*}{ Items } & \multicolumn{6}{|c|}{ Component } \\
\hline & 1 & 2 & 3 & 4 & 5 & 6 \\
\hline Eigenvalues & 5.24 & 3.42 & 2.40 & 2.16 & 1.70 & 1.26 \\
\hline$\%$ of variance explained & 18.7 & 11.6 & 8.6 & 7.7 & 6.1 & 4.5 \\
\hline I drink alcohol such as beer & .921 & & & & & \\
\hline I drink alcohol at social functions & .902 & & & & & \\
\hline Sometimes I take alcohol in bars & .908 & & & & & \\
\hline I drink alcohol with friends & .927 & & & & & \\
\hline I have been taking alcohol for at least the past one year & .879 & & & & & \\
\hline I smoke (e.g. cigarette) & & .877 & & & & \\
\hline I smoke at least three times in a day & & .958 & & & & \\
\hline Sometimes I smoke at home & & .960 & & & & \\
\hline I do not know the negative effect of salt on my physical health & & & .725 & & & \\
\hline I do not eat a variety of fruits & & & .563 & & & \\
\hline I do not know the negative effect of fried foods on my physical health & & & .769 & & & \\
\hline
\end{tabular}




\begin{tabular}{|c|c|c|c|c|c|c|}
\hline \multirow{2}{*}{ Items } & \multicolumn{6}{|c|}{ Component } \\
\hline & 1 & 2 & 3 & 4 & 5 & 6 \\
\hline Eigenvalues & 5.24 & 3.42 & 2.40 & 2.16 & 1.70 & 1.26 \\
\hline$\%$ of variance explained & 18.7 & 11.6 & 8.6 & 7.7 & 6.1 & 4.5 \\
\hline I do not eat a lot of fresh vegetables & & & .639 & & & \\
\hline I tend to consume more meat than fish & & & .395 & & & \\
\hline I eat foods that are high in carbohydrate such as rice, gari, yam, fufu, banku and Tuo Zafi (TZ) & & & .356 & & & \\
\hline I do not engage in ordinary walking for at least 30 minutes once or twice in a week & & & & .707 & & \\
\hline I do not engage in brisk walking & & & & .747 & & \\
\hline I do not jog or run & & & & .811 & & \\
\hline I do not ride bicycle & & & & 641 & & \\
\hline I do not participate in household activities such as cleaning, weeding and gardening & & & & .346 & & \\
\hline I eat food cooked with salt & & & & & 681 & \\
\hline Sometimes I sprinkle table salt on my food & & & & & .341 & \\
\hline I eat salted fried products (e.g. fish, eggs and plantain) & & & & & .773 & \\
\hline I eat salted food products (e.g. bread, sausage, cheese and butter) & & & & & 662 & \\
\hline I eat fried foods such as fried chicken, rice, yaw and plantain & & & & & .518 & \\
\hline I take food products such as cakes, plantain chips, biscuits and soft drinks. & & & & & & .639 \\
\hline Sometimes I take one or two snacks in a day & & & & & & .745 \\
\hline
\end{tabular}

Factor 1 consisted of five items which accounted for $18.73 \%$ of the variance of the score on the items. These items are related to the alcohol intake of an individual with a factor loading ranging from .88 to .92. This factor comprised items as "I drink alcohol such as beer", I drink alcohol at social functions", "sometimes I take alcohol in bars", "I drink alcohol with friends" and "I have been taking alcohol for at least the past one year". The name that best described this factor was "Alcohol Intake"

Factor 2 contained 3 items that accounted for $11.58 \%$ of the total variance. The factor loadings ranged from .88 to .96 . These items assessed the smoking behaviour of the respondents. "I smoke (e.g. cigarette)", "I smoke at least three times in a day" and "Sometimes I smoke at home", were the items that clustered in factor 2 . Since these items are related to smoking, the factor was named "Smoking."

Factor 3, which consisted of 6 items and accounted for $8.56 \%$ of the total variance of the health behaviour scores contained items that assessed the dietary behaviours. Hence factor three was identified as "Dietary Behaviour". The factor loadings of the items ranged from .36 to .77. These health behaviours were the eating habits of respondents. These items were "I do not know the negative effect of salt on my physical health", I do not eat a variety of fruits", "I do not know the negative effect of fried foods on my physical health", "I tend to consume more meat than fish", "I do not eat a lot of fresh vegetables" and "I eat food that are high in carbohydrate such as rice, gari, yam, fufu, banku and Tuo Zafi (TZ)".

Factor 4 contained 5 items that accounted for $7.72 \%$ of the total variance. The factor loadings ranged from .35 to .81 . Items in this factor described respondents' engagement in physical exercises. The items in this factor were "I do not participate in household activities such as cleaning, weeding and gardening", "I do not engage in brisk walking", "I do not jog or run" and "I do not engage in ordinary walking for at least 30 minutes once or twice in a week". Factor 4 was, therefore, labelled "Physical Exercise".

Factor 5 consisted of a group of 5 items which accounts for $6.09 \%$ of the total variance of the scores on the health behaviour inventory. These items deal with the salt intake of respondents. The factor loadings ranged from .34 to .77. These health behaviours were "I eat food cooked with salt", Sometimes I sprinkle table salt on my food", "I eat salted fried products (e. g. fish, eggs and plantain)", "I eat salted food products (e.g. bread, sausage, cheese and butter)" and "I eat fried foods such as fried chicken, rice, yaw and plantain". Thus, factor 5 was identified as "Salt Intake".

Factor 6 comprised 2 items that accounted for $4.49 \%$ of the total variance. The factor loading ranged from .64 to .75. "I take food products such as cakes, plantain chips, biscuits and soft drinks" and "sometimes I take one or two snacks in a day" were the items that loaded on factor 6 . The last factor was described as "Weight management". With the deletion of two items, the final version of the health behaviour inventory became a 26 -item with six factors. 


\subsection{Internal Consistency Assessment}

Table 4 shows the reliability indices of the factors and the overall factor structure.

Table 4: Reliabilities of the Factors and the overall Factor Structure

\begin{tabular}{cccc}
\hline Factor & Cronbach's Alpha & Cronbach's Alpha Based on Standardized Items & N of Items \\
\hline 1 & .953 & .953 & 5 \\
2 & .933 & .947 & 3 \\
3 & .688 & .688 & 6 \\
4 & .714 & .708 & 5 \\
5 & .659 & .659 & 5 \\
6 & .516 & .517 & 2 \\
\hline Overall & .792 & .811 & 26 \\
\hline
\end{tabular}

The internal consistency of the health behaviour inventory was also examined using the Cronbach's alpha. The overall alpha value for the 26 items of the health behaviour inventory was moderate $(\alpha=$ .79). Factor 1 (Alcohol Intake) and factor 2 (Smoking) exhibited a strong internal consistency scores of $\alpha=.95$ and $\alpha=.93$ respectively. Factor 4 (Physical Exercise) also exhibited a moderate internal consistency of $\alpha=.71$. However, factor 3 (Dietary behaviour), factor 5 (Salt Intake) and factor 6 (Weight Management) subscales had a relatively low internal consistency of $\alpha=.69, \alpha=.66$ and $\alpha$ $=.52$ respectively.

\subsection{Correlation Matrix}

Inter item correlations were computed and the correlation matrix of the $\mathrm{HBI}$ is as indicated in Table 5.

Table 5: Inter-item Correlation Matrix

\begin{tabular}{lcccccc}
\hline Factors & $\begin{array}{c}\text { Alcohol } \\
\text { Intake }\end{array}$ & Smoking & $\begin{array}{c}\text { Dietary } \\
\text { Behaviour }\end{array}$ & $\begin{array}{c}\text { Physical } \\
\text { Exercise }\end{array}$ & $\begin{array}{c}\text { Salt } \\
\text { Intake }\end{array}$ & $\begin{array}{c}\text { Weight } \\
\text { management }\end{array}$ \\
\hline Alcohol Intake & 1.000 & .279 & .188 & .048 & .100 & .087 \\
Smoking & & 1.000 & .191 & .082 & .056 & .045 \\
Dietary Behaviour & & & 1.000 & .282 & .281 & .175 \\
Physical Exercise & & & & 1.000 & .099 & .081 \\
Salt Intake & & & & 1.000 & .341 \\
Weight management & & & & & & 1.000 \\
\hline
\end{tabular}

The results in Table 5 indicate that there is a positive correlation among all the subscales. This means that a respondent who take in more alcohol is also likely to smoke much if this person is a smoker and vice versa. Similarly, a respondent who does not engage in any physical activities is also likely to not engage in any activities that would help reduce his or her weight.

\section{Conclusion}

The study investigated the factor structure and other psychometric properties of the newly developed Health Behaviour Inventory. The instrument was subjected to principal component factor analysis with the rotation method of Varimax with Kaiser Normalization. The Kaiser Meyer-Olkin index $(.808)$ and the Bartlett's test of Sphericity $\left.\left(x^{2}(581)=8133.626, p=0.000\right)\right)$ indicated that the data were suitable for factor analysis. Six factors were retained with an explained variance of $57.16 \%$. The alpha values of the subscales ranged from $.516-.953$. The overall reliability index of the instrument was .792. These indices indicate that the $\mathrm{HBI}$ is robust and has good internal consistency. This is the first study to explore the psychometric properties of an HBI. Future researchers need to take up the challenge to refine the instrument. It is, therefore, recommended 
that further investigations into other psychometric properties (such as the predictive validity) of the instrument be conducted with the view to making it a viable instrument for measuring health behaviour in Ghana.

\section{Implications for $\mathrm{HBI}$ Assessment and Counselling}

The findings from this study represent an initial good attempt at establishing the psychometric properties of an instrument that could be used to assess the health behaviour of clients. If further investigations into the psychometric properties of the $\mathrm{HBI}$ are favourably, then it may be a viable instrument for assessing the health behaviour of people within the stages of hypertension (i.e., normal blood pressure, prehypertension and hypertension). This could aid in the identification of individuals who may require counselling on lifestyle modifications. In other words, the instrument could be adapted as a screening device or diagnostic tool after its predictive validity has been established. Doctors, nurses, counsellors and clinical/health psychologists would use it to measure the health behaviour of their clients. Consequently, counselling can be introduced to modify poor health behaviour in order to help prevent or control high blood pressure and other chronic diseases among the Ghanaian adult population. Health behaviour counselling would complement drug therapy and this may lead to better health outcomes.

\section{References}

Addo, J., Amoah, A. G. B., \& Koram, K. A. (2006). The changing patterns of hypertension in Ghana: A study of four rural communities in the Ga District. Ethnicity and Disease, 16, 894-899.

Agyemang, C., Bruijnzeels, M. A., \& Owusu-Dabo, E. (2006). Factors associated with hypertension awareness, treatment and control in Ghana, West Africa. Journal of Human Hypertension, 20, 67-71.

Bhatt, S. P., Luqman-Arafath, T. K. \& Guleria, R. (2007). Non-pharmacological management of hypertension. Indian Journal of Medical Sciences, 61 (11), 616-624.

Costa, F.V. (2002). Non-pharmacological treatment of hypertension in women. Journal of Hypertension, 20 (suppl.2), S57-S61.

Field, A. P. (2013). Discovering statistics using IBM SPSS Statistics ( $4^{\text {th }}$ ed.). London: Sage.

Forrester, T., Adeyemo, A., Soarres-Wynter, S., Sargent, L., Bennett, F., Wilks, R., Luke, A., Prewitt, E., Kramer, H. \& Cooper, R. S. (2005). A randomized trial on sodium reduction in two developing countries. Journal of Hypertension, 19, 55-60.

Henson, R. K., \& Roberts, J. K. (2006). Use of exploratory factor analysis in published research: Common errors and some comment on improved practice. Educational and Psychological Measurement, 66(3), 393-416.

Hutcheson, G., \& Sofroniou, N. (1999). The multivariate social scientist. London: Sage.

Jepson, R. G., Harris, F. M., Platt, S., \& Tannahill, C. (2010). The effectiveness of interventions to change six health behaviours: A review of reviews. BMC Public Health, 10:538. Retrieved from http://www.biomedcentral.com/1471-2458/10/538.

Kaplan, N. M. (1987). Non-pharmacological treatment of hypertension. Proceedings of the Nutrition Society, 46, 373-377.

Nadar, S. \& Lip, G. (2011). Non-pharmacological management of hypertension. http://oxfordmedicine.com /view/10.1093/med/9780199547579.001 Retrieved on January, 20, 2013.

Ribeiro, A. G., Ribeiro, S. M. R., Dias, C. M. G. C., Ribeiro, A. Q., Castro, F. A. F., Suarez-Varela \& Cotta, R. M. M. (2011). Non-pharmacological treatment of hypertension in primary health care: A comparative clinical trial of two education strategies in health and nutrition. Retrieved from http://www.biomedcentral.com/1471-2458/11/637.

Sainani, G. S. (2003). Non-drug therapy in prevention and control of hypertension. JAPI, 51, 1001-1006.

Sharma, M. J. Frishman, W. H. \& Ghandhi, K. (2011). Resperate: Non-pharmacological treatment of hypertension. Cardiology Review, 19 (2), 47-51.

Wexler, R. \& Aukerman, G. (2006). Non-pharmacologic strategies for managing hypertension. American Family Physician, 73 (11), 1953-196. 